\title{
Does Body Mass Index Influence the Outcomes After Surgery for Locally Advanced Prostate Cancer?
}

\author{
Chao-Yu Hsu ${ }^{1}$, Steven Joniau ${ }^{1}$, Raymond Oyen ${ }^{2}$, Tania Roskams ${ }^{3}$ and Hein Van Poppel ${ }^{1, *}$
}

Department of ${ }^{1}$ Urology, ${ }^{2}$ Radiology and ${ }^{3}$ Histopathology, University Hospitals, KULeuven Belgium

\begin{abstract}
Introduction: A higher body mass index (BMI) has been correlated with worse outcome after radical prostatectomy (RP), but this observation has been mainly noticed in clinically localized disease. The objective of this study is to analyze the relationship between BMI and outcome of surgery for clinical unilateral T3a (cT3a) prostate cancer.

Patients and Methods: Two hundred patients with cT3a prostate cancer underwent RP between 1987 and 2004. The BMI of each patient was recorded before surgery. Patients were divided into 2 groups: BMI $<25$ and $\geq 25$. The Cox proportional hazard analysis was used to study the differences in outcome between these two groups.

Results: The mean age was 63.3 years (range 41 to 79). The mean follow-up was 70.6 months (range 7 to 177). Ninetythree patients had BMI $<25$, and 107 patients had BMI $\geq 25$. There were no significant differences between BMI $<25$ and $\geq 25$ in the incidence of node positive disease ( $\mathrm{p}=0.22$ ) and margin status $(\mathrm{p}=0.48)$. Neither were there significant differences between these two groups in pre-operative PSA $(\mathrm{p}=0.15)$ and cancer volume $(\mathrm{p}=0.07)$. In the Cox proportional hazard analysis, BMI was a significant predictor in clinical progression free survival (CPFS).

Conclusion: BMI has been correlated with worse outcome after RP in clinically localized disease. We could confirm this observation in CPFS of cT3a disease. However, while oncological outcomes seem to differ, this type of surgery may be very demanding and postoperative short-term morbidity may also be higher in patients with $\mathrm{BMI} \geq 25$.
\end{abstract}

Key Words: Body mass index, cT3, prostate cancer.

\section{INTRODUCTION}

Body mass index (BMI) (also called the "Quetelet index") was invented by a Belgian mathematician Lambert Adolphe Quetelet in 19th century. Now it is the most widely used tool to measure the status of obesity. BMI is defined as the body weight divided by square of height, with overweight defined as an index of more than 25 .

In a large cohort study of 950000 Norwegian men followed for an average of 21 years, Engeland et al. found that the effect of BMI on the incidence of prostate cancer was modest [1]. Bradbury et al. found that obese men (BMI $\geq 30$ ) were at lower risk of developing prostate cancer compared to normal weight men [2]. Giovannucci et al. agreed on this point, they considered that the risk of prostate cancer in men with a higher BMI $(\geq 30)$ was lower than in men with a lower BMI (23-24.9) but only if they were younger $(<60$ years old) [3]. This was also shown by Porter et al., who found that men with a BMI $>29$ had the lowest risk of prostate cancer. They concluded that obesity is inversely related to prostate cancer risk in middle-aged (40-64 years old) men [4]. Recently studies by Kurahashi et al. and Baillargeon et al., both of them described that BMI was not significantly associated with risk of prostate cancer [5,6]. Presti et al. categorized BMI of 787 patients into 3 groups (normal: <25, overweight: 25-29.9 and obese: >30), they found detection rates of prostate cancer were highest in the normal group

*Address correspondence to this author at the Department of Urology, University Hospital Leuven, Herestraat 49, 3000 Leuven, Belgium; Tel: 00-3216 34.66.87; Fax: 00-32-16 34.69.31;

E-mail: Hendrik.VanPoppel@uzleuven.be
(52\%) compared to overweight (37\%) and obese (42\%) [7]. A more detailed analysis was performed by Kobayashi et al., who stratified 481 men with TRUS biopsy into 3 BMI groups (BMI <23, 23-25, >25). Similar to the result by Presti et al., they found no significant differences between cancer detection rate and BMI groups on univariate analysis, but there was a significant association between BMI and cancer detection on multivariate analysis. They concluded that BMI had a significant impact on prostate cancer detection rate [8].

BMI might correlate with worse outcome after radical prostatectomy (RP), but this observation has been mainly noticed in clinically localized disease. The objective of this study is to investigate the correlation between BMI and outcomes of surgery for locally advanced prostate cancer in a single center series.

\section{PATIENTS AND METHODS}

\section{Population of Patients}

Between 1987 and 2004, 235 patients with clinical unilateral T3a prostate cancer detected by digital rectal examination (DRE) underwent RP and bilateral pelvic lymphadenectomy at our institution. Thirty-five patients who received neoadjuvant treatment before surgery were excluded. Two hundred patients were included in the final analysis. They were selected for operation on the basis of limited, unilateral cT3a, any Gleason score, any PSA and Eastern Cooperative Oncology Group (ECOG) performance status 01. All patients had negative finding on both contrast enhanced computed tomography of the pelvis and bone scan. 
The patients were categorized into 2 subgroups according to the BMI at surgery: $<25$ and $\geq 25$.

The last serum PSA value obtained prior to prostate biopsies was used in the analysis. Surgery was performed by one of 2 senior surgeons according to the technique as previously described [9]. The pathological reports were recorded, and lymph node status was assigned, based on the 2002 TNM classification [10]. Status of surgical margin and cancer volume were also recorded.

Biochemical progression was defined as any serum PSA $\geq 0.2 \mathrm{ng} / \mathrm{ml}$, clinical progression was defined as local recurrence or distant metastasis according to previous description [11]. Local recurrence was defined as the presence of cancer cells at the pelvic area proven by pathological examination. Distant metastasis was defined as tumor detected by bone scan, CT or MRI outside the pelvic area. Cancer-specific survival (CSS) was defined as the time from RP to death due to prostate cancer or complications of this disease. Overall survival (OS) was defined as the time from RP to death by any cause.

\section{Statistical Analysis}

All categorical variables (nodal status, margin and pathological stage) were analyzed by chi-square analysis or Fisher's exact test, continuous variables (age, preoperative PSA and cancer volume) were compared by one-way analysis of variance or Mann-Whitney test. The Cox proportional hazard analysis was used to determine the prognostic indicators of disease progression. The Kaplan-Meier method was used to analyse biochemical progression free survival (BPFS) and clinical progression free survival (CPFS), CSS and OS. The differences between subgroups were tested by log-rank test. MedCalc ${ }^{\circledR}$ statistical software, version 8.1.0.0 (MedCalc Software, Belgium) and SPSS v12.0 were used for the analysis.

\section{RESULTS}

Ninety-three patients had BMI <25, and 107 patients had $\mathrm{BMI} \geq 25$. The patient's characteristics and pathological findings were listed in Table 1. The mean age was 63.3 years (range 41 to 79). The mean follow-up was 70.6 months (range 7 to 177). The average preoperative PSA was 14.9 $\mathrm{ng} / \mathrm{ml}$ (range 1.0-127.0). Forty-seven patients (23.5\%) were confirmed with organ confined disease (pT2), $145(72.5 \%)$ were pT3 including 113 (56.5\%) with extraprostatic extension only and $32(16 \%)$ with seminal vesicle invasion. Eight patients (4\%) had adjacent structure invasion (pT4). Seventeen patients $(8.5 \%)$ were found with lymph node involvement, 67 patients $(33.5 \%)$ had positive surgical margin. Both median biopsy and surgical Gleason score were 7 . One hundred twelve patients $(56 \%)$ received adjuvant or salvage treatment (ADT, RT or both) after RP. Local recurrence was found in 4 patients, distant metastasis was found in 13 patients. Seven patients died of prostate cancer, 15 patients died of other causes.

There were no significant differences between BMI $<25$ and $\geq 25$ in the incidence of positive pelvic lymph node $(\mathrm{p}=0.22)$ and positive surgical margin $(\mathrm{p}=0.48)$. Neither were there significant differences between these two groups in age $(\mathrm{p}=0.84)$, pre-operative PSA $(\mathrm{p}=0.15)$, cancer volume $(\mathrm{p}=0.07)$, surgical Gleason score $(\mathrm{p}=0.17)$ and pathological stage $(\mathrm{p}=0.49)$ (Table $\mathbf{1})$.

In patients with BMI <25, margin status, pathological stage and preoperative PSA were significant predictors in BPFS on univariate analysis; however margin status was the only significant predictor on multivariate analysis (Table 2). In patients with $\mathrm{BMI} \geq 25$, except Gleason score all the parameters were significant predictors in BPFS on univariate analysis; margin and node status were significant predictors on multivariate analysis (Table $\mathbf{3}$ ).

In all, on Cox multivariate analyses, BMI and surgical Gleason score were independent predictive factors in CPFS.

Table 1. The Patient's Characteristics

\begin{tabular}{|c|c|c|c|}
\hline Patient number & 93 & 107 & \\
\hline Mean PSA ng/ml (range) & $13.32(1.00-57.92)$ & $16.23(1.20-127.00)$ & 0.153 \\
\hline Positive node (n, \%) & $5(5.4 \%)$ & $12(11.2 \%)$ & 0.222 \\
\hline Mean cancer volume (ml) (range) & $5.69(0.25-27.70)$ & $7.73(0.20-31.00)$ & 0.074 \\
\hline Median surgical Gleason score (range) & $7(5-9)$ & $7(4-9)$ & 0.168 \\
\hline \multicolumn{4}{|l|}{ Pathological stage (n, \%) } \\
\hline $\mathrm{T} 4$ & $2(2.2 \%)$ & $6(5.6 \%)$ & \\
\hline
\end{tabular}


Table 2. The Cox Proportional Univariate and Multivariate Analyses of Biochemical Progression Free Survival (BPFS) in 93 Patients with BMI $<25$

\begin{tabular}{|c|c|c|c|c|c|c|}
\hline \multirow{2}{*}{ Parameters } & \multicolumn{3}{|c|}{ Univariate Analysis } & \multicolumn{3}{c|}{ Multivariate Analysis } \\
\cline { 2 - 6 } & HR & $\mathbf{9 5 \%}$ CI & P value & HR & 95\% CI & P value \\
\hline \hline Cancer Volume & 1.027 & $0.975-1.081$ & 0.320 & 0.979 & $0.916-1.046$ & 0.524 \\
\hline Gleason score & 1.060 & $0.751-1.498$ & 0.741 & 1.063 & $0.740-1.528$ & 0.741 \\
\hline Margin & 3.302 & $1.667-6.538$ & $<0.001$ & 2.337 & $1.069-5.110$ & 0.034 \\
\hline Node & 1.768 & $0.544-5.744$ & 0.346 & 0.736 & $0.191-2.837$ & 0.657 \\
\hline Pathological stage & 1.663 & $1.036-2.669$ & 0.036 & 1.519 & $0.821-2.812$ & 0.185 \\
\hline Preoperative PSA & 1.036 & $1.011-1.061$ & 0.004 & 1.028 & $0.998-1.059$ & 0.067 \\
\hline
\end{tabular}

Table 3. The Cox Proportional Univariate and Multivariate Analyses of Biochemical Progression Free Survival (BPFS) in 107 Patients with $\mathrm{BMI} \geq \mathbf{2 5}$

\begin{tabular}{|c|c|c|c|c|c|c|}
\hline \multirow{2}{*}{ Parameters } & \multicolumn{3}{|c|}{ Univariate Analysis } & \multicolumn{3}{c|}{ Multivariate Analysis } \\
\cline { 2 - 7 } & HR & $\mathbf{9 5 \%}$ CI & P value & HR & 95\% CI & P value \\
\hline \hline Cancer Volume & 1.079 & $1.035-1.124$ & $<0.001$ & 1.050 & $0.999-1.104$ & 0.055 \\
\hline Gleason score & 1.031 & $0.768-1.385$ & 0.839 & 0.801 & $0.589-1.090$ & 0.161 \\
\hline Margin & 3.733 & $2.047-6.806$ & $<0.001$ & 2.884 & $1.525-5.453$ & 0.001 \\
\hline Node & 3.837 & $1.826-8.063$ & $<0.001$ & 2.587 & $1.170-5.721$ & 0.020 \\
\hline Pathological stage & 2.399 & $1.620-3.553$ & $<0.001$ & 1.572 & $0.949-2.603$ & 0.081 \\
\hline Preoperative PSA & 1.016 & $1.003-1.030$ & 0.021 & 1.002 & $0.983-1.020$ & 0.870 \\
\hline
\end{tabular}

Table 4. The Multivariate Analyses in BPFS, CPFS and OS

\begin{tabular}{|c|c|c|c|c|c|c|c|c|c|}
\hline \multirow{2}{*}{ Covariates } & \multicolumn{3}{|c|}{ BPFS } & \multicolumn{3}{|c|}{ CPFS } & \multicolumn{3}{|c|}{ OS } \\
\hline & HR & $95 \% \mathrm{CI}$ & $\mathbf{p}$ & HR & $95 \% \mathrm{CI}$ & $\mathbf{p}$ & HR & $95 \% \mathrm{CI}$ & $\mathbf{p}$ \\
\hline Preoperative PSA & 1.02 & $1.01-1.04$ & $<0.01$ & 0.95 & $0.88-1.02$ & 0.13 & 1.01 & $0.99-1.03$ & 0.40 \\
\hline Surgical Gleason score & 1.17 & $0.65-2.10$ & 0.59 & 0.16 & $0.03-0.89$ & 0.04 & 0.64 & $0.25-1.65$ & 0.36 \\
\hline Node & 0.81 & $0.36-1.79$ & 0.69 & 0.99 & $0.10-10.34$ & 0.99 & 0.57 & $0.17-1.86$ & 0.35 \\
\hline Margin & 1.15 & $0.63-2.09$ & 0.66 & 2.76 & $0.42-18.38$ & 0.29 & 0.66 & $0.24-1.88$ & 0.44 \\
\hline Cancer volume & 1.02 & $0.98-1.06$ & 0.44 & 1.06 & $0.96-1.16$ & 0.29 & 1.08 & $1.01-1.15$ & 0.02 \\
\hline BMI & 0.99 & $0.92-1.06$ & 0.71 & 1.93 & $1.23-3.02$ & $<0.01$ & 1.01 & $0.86-1.17$ & 0.98 \\
\hline
\end{tabular}

Preoperative PSA was an independent predictor in BPFS. Cancer volume was an independent factor in OS (Table 4). In Kaplan-Meier analysis, there was a significant difference between BMI $<25$ and $\geq 25$ in OS ( $p=0.547$ in BPFS, 0.052 in CPFS, 0.229 in CSS and 0.045 in OS) (Fig. 1A, 1B, 1C,
1D). At 5 years, BPFS was $62.4 \%$ in the group with BMI $<25$ and $57.4 \%$ in the group with BMI $\geq 25$, CPFS was $100 \%$ and $92.4 \% \%$, CSS was $100 \%$ and $97.5 \%$, and OS was $98.7 \%$ and $93.4 \%$ respectively. 
1A

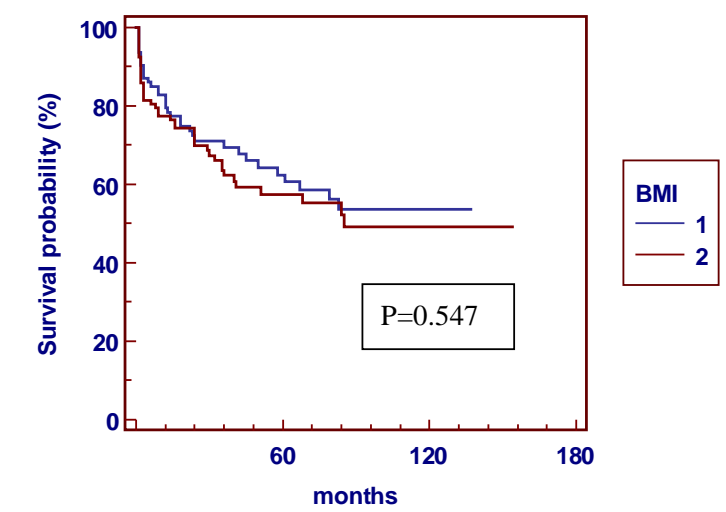

\begin{tabular}{|ll|c|c|c|c|}
\hline Months & & 0 & 60 & 120 & 180 \\
\hline Patients at risk (BPFS) & BMI $<25$ & 93 & 34 & 5 & 0 \\
& BMI $\geq 25$ & 107 & 30 & 1 & 1 \\
\hline
\end{tabular}

$1 \mathrm{C}$

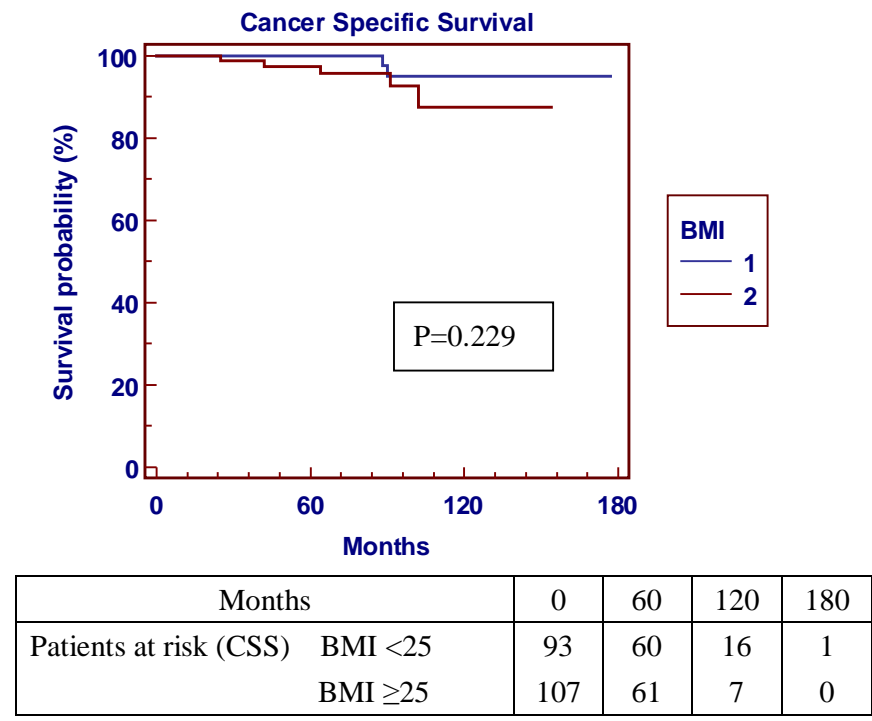

1B

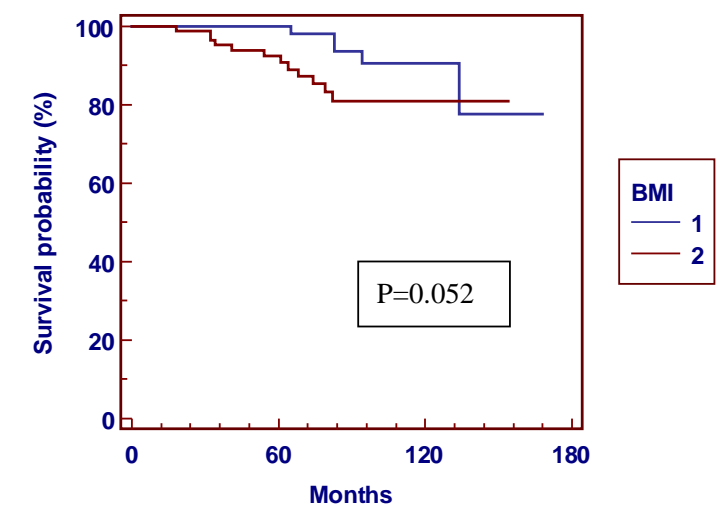

\begin{tabular}{|cl|c|c|c|c|}
\hline \multicolumn{2}{|c|}{ Months } & 0 & 60 & 120 & 180 \\
\hline Patients at risk (CPFS) & BMI $<25$ & 93 & 60 & 15 & 1 \\
& BMI $\geq 25$ & 107 & 57 & 5 & 0 \\
\hline
\end{tabular}

1D

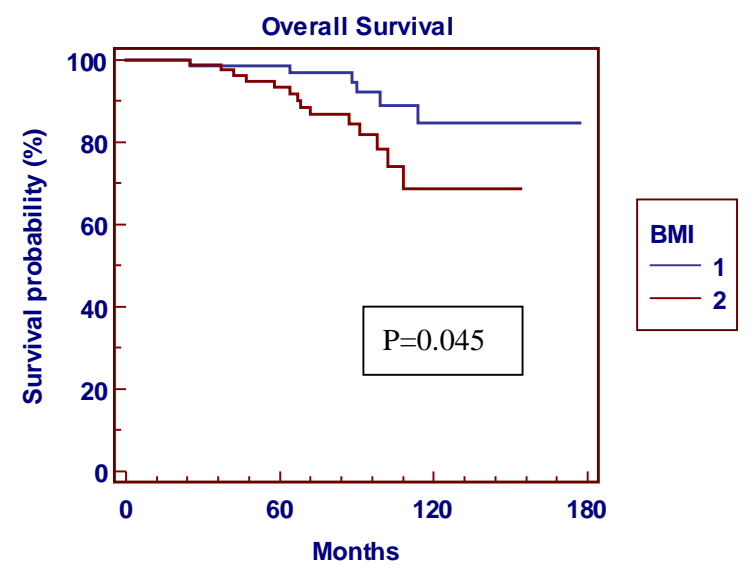

\begin{tabular}{|cc|c|c|c|c|}
\hline \multicolumn{2}{|c|}{ Months } & 0 & 60 & 120 & 180 \\
\hline Patients at risk (OS) $\quad$ BMI $<25$ & 93 & 60 & 16 & 1 \\
& BMI $\geq 25$ & 107 & 61 & 7 & 0 \\
\hline
\end{tabular}

Fig. (1). The survival outcomes between $\mathrm{BMI}<25$ and $\mathrm{BMI} \geq 25$ (1: $\mathrm{BMI}<25,2$ : $\mathrm{BMI} \geq 25)$.

\section{DISCUSSION}

Obesity has been a problem in western countries for a long time. In this article, we compared the outcomes of the patients with BMI $<25$ and $\geq 25$ in locally advanced T3a prostate cancer. Margin status was proved a predictive factor in BPFS, either BMI $<25$ or $\geq 25$. For the patients with BMI $\geq 25$, node status should be noted.

\section{BMI and Surgical Margin}

Obesity has been associated with higher incidence of positive surgical margins, [12,13]. A recently report by Magheli et al., 5631 patients were enrolled in this study, concluded that lower BMI was significantly associated with lower rates of positive surgical margin [14]. For locally advanced prostate cancer, although there was no significant difference in status of margin between $\mathrm{BMI}<25$ and $\geq 25$, we proved status of surgical margin was an independent predictive factor in BPFS either in $\mathrm{BMI}<25$ and $\geq 25$. A positive surgical margin was found in 67 patients $(33.5 \%)$. When we analysed the evolution of positive surgical margins in time, the positive margin rates improved dramatically from $66.7 \%$ in the period 1987-1994 to $43.3 \%$ in the period 1995-1999 to $10.0 \%$ in the period 2000-2004. It was clear that margin rate was improved with gaining more experience in surgery for cT3 prostate cancer.

\section{BMI and Risk of High-Grade Prostate Cancer}

Baillargeon et al. reported that BMI was not associated with either high-grade or low-grade disease [6]. Contradictory opinions were reported by several authors. In a large 
series of 2952 prostate cancer patients with complete BMI information from CaPSURE (Cancer of the Prostate Strategic Urologic Research Endeavor), Kane et al. found that increased obesity was associated with a slightly increased chance of having high risk prostate cancer at diagnosis [15]. At the same time, Freedland et al. reported that a higher BMI was positively associated with being diagnosed with prostate cancer. They also found that a higher BMI increased the odds of high-grade disease in men with prostate cancer [16]. Gong et al. examined the relationship between obesity and the risk of low- or high-grade prostate cancer. They reported that compared with men with BMI $<25$, obese men (BMI $\geq 30$ ) had an $18 \%$ decreased risk of low-grade (Gleason <7) prostate cancer and a $29 \%$ increased risk of high-grade prostate cancer (Gleason $\geq 7$ ) or a $78 \%$ increased risk of Gleason score 8 to 10 . They concluded that obesity increases the risk of high-grade but decreases the risk of low-grade prostate cancer [17]. In current study, for cT3a prostate cancer, there was no significant difference in surgical Gleason score between the patients with $\mathrm{BMI}<25$ and $\geq 25$. Surgical Gleason score was not a predictor of BPFS. However, surgical Gleason score was an independent predictive factor in CPFS on multivariate analyses.

\section{BMI and Biochemical Progression After RP}

Strom et al. described that patients with $\mathrm{BMI} \geq 30$ had a higher rate of biochemical failure compared with non-obese men. They reported that a higher BMI was a significant independent predictor for biochemical progression after RP in multivariate analysis [18]. This opinion was shared by Bassett et al. who reported that the patients with a BMI $\geq 35$ were 1.69 times more at risk to experience biochemical failure than patients with normal weight (BMI <25). They considered that increasing BMI was significantly associated with biochemical progression [19]. A recently study by Hisasue et al., proved BMI to be an independent predictor for PSA recurrence on the multivariate analysis [20]. Freedland et al. reported that increasing BMI was associated with increasing odds of capsular incision. They found that mild obesity was associated with a $30 \%$ increase in odds of capsular incision, while moderate and severe obesity was associated with $57 \%$ increasing odds of capsular incision compared to normal weight patients [21]. The technique of retropubic RP is more difficult in obese patients. They also reported that increasing BMI was associated with high grade disease in the RP specimen, positive surgical margins, extraprostatic extension, lymph node metastasis and also increasing risk of biochemical progression [22]. These data showed obesity can influence the outcome after RP.

Several studies showed that a higher BMI correlates with a higher risk of biochemical progression in localized prostate cancer. However, in clinical unilateral T3a prostate cancer, we found BMI was not a predictor in BPFS and OS, but it was a significant predictor in CPFS.

In the current study, Kaplan -Meier analysis showed no significant differences for CPFS while Cox analysis did show significant differences. Because Cox analysis is a multivariate analysis, $p$ value may difference from Kaplan Meier analysis which is a uni-variate analysis.
The limitations of this study: the small number of patients. Not all clinical T3 cases agreed to undergo RP, they had the choice between RT or ADT. Most of our patients were Caucasians. Because of these limitations, further study may be required.

\section{CONCLUSION}

BMI has been correlated with worse outcome after RP in clinically localized disease. We could confirm this observation in CPFS of cT3a disease. Furthermore, besides the fact that oncological outcomes differ, this type of surgery may also be very demanding and postoperative short-term morbidity may also be higher in patients with $\mathrm{BMI} \geq 25$.

\section{REFERENCES}

[1] Engeland A, Tretli S, Bjorge T. Height, body mass index, and prostate cancer: a follow-up of 950000 Norwegian men. Br J Cancer 2003; 89(7): 1237-42.

[2] Bradbury BD, Wilk JB, Kaye JA. Obesity and the risk of prostate cancer (United States). Cancer Causes Control 2005; 16(6): 637-41.

[3] Giovannucci E, Rimm EB, Liu Y, et al. Body mass index and risk of prostate cancer in U.S. health professionals. J Natl Cancer Inst 2003; 95(16): 1240-4.

[4] Porter MP, Stanford JL. Obesity and the risk of prostate cancer. Prostate 2005; 62(4): 316-21.

[5] Kurahashi N, Iwasaki M, Sasazuki S, Otani T, Inoue M, Tsugane S Association of body mass index and height with risk of prostate cancer among middle-aged Japanese men. Br J Cancer 2006; 94(5): 740-2.

[6] Baillargeon J, Platz EA, Rose DP, et al. Obesity, adipokines, and prostate cancer in a prospective population-based study. Cancer Epidemiol Biomarkers Prev 2006; 15(7): 1331-5.

[7] Presti JC Jr, Lee U, Brooks JD, Terris MK. Lower body mass index is associated with a higher prostate cancer detection rate and less favorable pathological features in a biopsy population. J Urol 2004; 171(6 Pt 1): 2199-202.

[8] Kobayashi T, Mitsumori K, Nishizawa K, Kawahara T, Ogura K, Ide Y. Association between body mass index and prostate cancer detection rates in Japanese urologic patients. Urology 2005; 66(1): 130-4.

[9] Hsu CY, Joniau S, Van Poppel H. Radical prostatectomy for locally advanced prostate cancer; technical aspects of radical prostatectomy. EAU Update Series 2005; 3: 90-7.

[10] Sobin LH, Wittekind C. TNM Classification of prostate cancer. 6th ed. Wiley-Liss: New York 2002; pp. 184-7.

[11] Hsu CY, Joniau S, Oyen R, Roskams T, Van Poppel H. Outcome for clinical unilateral T3a prostate cancer; a single-institution experience. Eur Urol 2007; 51(1): 121-9.

[12] Herman MP, Raman JD, Dong S, Samadi D, Scherr DS. Increasing body mass index negatively impacts outcomes following robotic radical prostatectomy. JSLS 2007; 11(4): 438-42.

[13] Castle EP, Atug F, Woods M, Thomas R, Davis R. Impact of body mass index on outcomes after robot assisted radical prostatectomy. World J Urol 2008; 26(1): 91-5.

[14] Magheli A, Rais-Bahrami S, Trock BJ, et al. Impact of body mass index on biochemical recurrence rates after radical prostatectomy; An analysis utilizing propensity score matching. Urology 2008; 72(6): 1246-51.

[15] Kane CJ, Bassett WW, Sadetsky N, et al. Obesity and prostate cancer clinical risk factors at presentation; data from CaPSURE. J Urol 2005; 173(3): 732-6.

[16] Freedland SJ, Terris MK, Platz EA, Presti JC Jr. Body mass index as a predictor of prostate cancer; development versus detection on biopsy. Urology 2005; 66(1): 108-13.

[17] Gong Z, Heuhouser ML, Goodman PJ, et al. Obesity diabetes, and risk of prostate cancer; results from the prostate cancerprevention trial. Cancer Epidemiol Biomarkers Prev 2006; 15(10): 1977-83.

[18] Strom SS, Wang X, Pettaway CA, et al. Obesity, weight gain, and risk of biochemical failure among prostate cancer patients following prostatectomy. Clin Cancer Res 2005; 11(19 Pt 1): 6889-94. 
[19] Bassett WW, Cooperberg MR, Sadetsky N, et al. Impact of obesity on prostate cancer recurrence after radical prostatectomy; data from CaPSURE. Urology 2005; 66(5): 1060-5.

[20] Hisasue S, Yanase M, Shindo T, et al. Influence of body mass index and total testosterone level on biochemical recurrence following radical prostatectomy. Jpn J Clin Oncol 2008; 38(2): 12933 .
[21] Freedland SJ, Grubb KA, Yiu SK, et al. Obesity and capsular incision at the time of open retropubic radical prostatectomy. J Urol 2005; 174: 1798-801.

[22] Freedland SJ, Grubb KA, Yiu SK, et al. Obesity and risk of biochemical progression following radical prostatectomy at a tertiary care referral center. J Urol 2005; 174: 919-22.

(C) Hsu et al.; Licensee Bentham Open.

This is an open access article licensed under the terms of the Creative Commons Attribution Non-Commercial License (http://creativecommons.org/licenses/ by-nc/3.0/) which permits unrestricted, non-commercial use, distribution and reproduction in any medium, provided the work is properly cited. 